\title{
Cidades verdes: uma análise do Plano Diretor de Arborização Urbana do município de Salvador (BA)
}

\author{
Green cities: an analysis of the Urban Arborization Master Plan of the \\ municipality of Salvador (BA)
}

\section{Marcos Paulo Sales' ${ }^{10}$, Geraldo Jorge Barbosa de Moura"ID, André Augusto Araújo Oliveira"ID, Ronaldo Souza Piber"III}

\author{
' Universidade de São Paulo, São Paulo, Brasil \\ "Universidade Católica do Salvador, Salvador, BA, Brasil \\ III Universidade Paulista, São Paulo, Brasil
}

\section{RESUMO}

O ato de arborizar as cidades é primordial para a dinâmica nas zonas urbanas, seja do ponto de vista funcional, da biodiversidade ou do impacto na qualidade de vida das populações. Como descrito pela ciência, o ato de arborizar zonas urbanas resulta em uma série de benefícios: conforto climático e ambiental, recuperação da fauna e flora locais, melhoria do impacto visual e paisagístico ou mesmo para regular o microclima urbano. Este estudo teve como objetivos analisar os desafios, perspectivas e possibilidades da arborização urbana no município de Salvador (BA), a partir da aprovação do Plano Diretor de Arborização Urbana (PDAU). As etapas metodológicas consistiram em pesquisa bibliográfica e documental, que incluíram a análise do PDAU, implementado pela Lei n 9.187/2017, e levantamento de dados em fontes de pesquisa secundárias como leis, artigos, periódicos e relatórios. De acordo com levantamentos realizados em base de dados do IBGE, observamos que o município de Salvador ocupa a penúltima posição nos índices de arborização urbana entre as capitais do Nordeste, perdendo apenas para o município de São Luís (MA). A partir da homologação do PDAU como instrumento legal, concluímos que a sua implantação é essencial para uma melhor gestão municipal, que deve orientar, a partir de critérios técnicos estabelecidos, o planejamento das áreas verdes do município, além de oferecer melhor qualidade de vida para a população e favorecer a manutenção da biodiversidade local.

Palavras-chave: Arborização urbana; Áreas verdes; PDAU; Lei 9.187/2017; Gestão pública 


\section{ABSTRACT}

The act of foresting cities is essential for the dynamics in urban areas, whether from the functional point of view, biodiversity or the impact on the quality of life of the populations. As described by science, the act of afforesting urban areas results in a series of benefits: climatic and environmental comfort, recovery of local fauna and flora, improvement of the visual and landscape impact or even to regulate the urban microclimate. This study aimed to analyze the challenges, perspectives and possibilities of urban afforestation in the city of Salvador (BA), after the approval of the Urban Afforestation Master Plan (PDAU). The methodological steps consisted of bibliographic and documentary research, which included the analysis of the PDAU, implemented by Law No. 9,187 / 2017, and data collection from secondary research sources such as laws, articles, journals and reports. According to surveys carried out in the IBGE database, we observed that the municipality of Salvador occupies the penultimate position in the urban afforestation indexes among the capitals of the Northeast, second only to the municipality of São Luís (MA). From the approval of the PDAU as a legal instrument, we concluded that its implementation is essential for better municipal management, which should guide, based on established technical criteria, the planning of the city's green areas, in addition to offering a better quality of life for the population and favor the maintenance of local biodiversity.

Keywords: Urban afforestation; green areas; PDAU; Law 9,187 / 2017; Public management

\section{INTRODUÇÃO}

O processo da arborização urbana evoluiu ao longo do tempo e é registrado em diversas civilizações (BERNATZKY, 1980). Desde o momento em que o ser humano passou a viver em sociedade, a importância e o significado das árvores no processo de composição urbanística assumiram significados diversos. As árvores servem tanto para estimular e incentivar a convivência humana em comunidades, quanto para melhorar a qualidade de vida das populações ou embelezar as cidades ao assumir um caráter paisagístico e estético (BONAMETTI, 2003).

A ação antrópica, que transforma o ambiente natural das cidades e, consequentemente, atua na arborização urbana, ganha destaque em Pinheiro e Souza (2017). Esta ação se acentua a partir do crescimento demográfico e territorial sem um planejamento efetivo, situação que favorece o desmatamento de áreas verdes para criar espaços que darão lugar a ocupações diversas: casas, prédios, loteamentos, vias de acesso, equipamentos públicos e mobiliário urbano. Obras voltadas para a habitação e infraestrutura podem facilitar a dinâmica das 
cidades, porém, sem um planejamento eficiente, comprometem a fauna e flora locais e podem aumentar consideravelmente os custos com manutenção e infraestrutura.

Dados do IBGE (2010) apontam que o crescimento populacional nas cidades do Brasil é crescente e constante, o que sugere uma demanda maior das populações por habitação e serviços públicos diversos. Na década de 1970, por exemplo, o percentual era de $55,9 \%$ de pessoas vivendo nas cidades. Em apenas 50 anos, estes índices tiveram um incremento de quase 30\%, passando para $84,4 \%$.

Na região Nordeste do Brasil, onde está localizado o município de Salvador, capital do estado da Bahia e foco de análise deste artigo, esse percentual é um pouco menor, com $73,1 \%$ da população vivendo nas cidades. Atualmente o município conta com uma população estimada em 2.886.698 pessoas (IBGE, 2020). Os números sugerem que o nordestino ainda resiste ao migrar da zona rural para se dedicar à vida nas zonas urbanas.

O município de Salvador ainda está distante do ideal de arborização. Atualmente ocupa a penúltima posição, entre as nove capitais do Nordeste, de acordo com o percentual de arborização em vias públicas (IBGE, 2010). No ranking estabelecido a partir destes dados, o município ocupa a penúltima posição, estando à frente apenas do município de São Luís, capital do Maranhão. Os melhores índices de arborização (IBGE, 2010) estão localizados nos municípios de João Pessoa (PB), seguido por Fortaleza (CE) e Teresina (PI), respectivamente.

A Embrapa (2000) defende que a arborização deve ser um serviço público essencial - que deve beneficiar as populações humanas e a biodiversidade - por promover uma reestruturação do espaço urbano. Os instrumentos legais são decisivos para estimular e ordenar a implementação de uma gestão urbana e ambiental eficientes, traçando limites e diretrizes para o plantio planejado e estruturado de árvores em espaços urbanos, bem como atenção especial às espécies escolhidas para este fim, que devem ser adequadas ao ambiente. 
A partir das contribuições de diversos estudos e nas ponderações aqui apresentadas, é verificável que o Estatuto das Cidades (2001) visa o equilíbrio ambiental nos ambientes urbanos, estabelece e garante o direito a uma cidade sustentável, entalhada de forma ampla no art. $2^{\circ}$, inciso I da Lei $n^{\circ} 10.257$, de 10 de julho de 2001, que regulamenta os artigos 182 e 183 da Constituição Cidadã e estabelece diretrizes da política urbana. Este artigo é tutelado não só pelo Estatuto das Cidades, mas também pelas leis 7.347/85 e 8.078/90.

Sobre os benefícios das árvores nas cidades, Taha (1997) destaca a amenização das temperaturas, conforto térmico e resfriamento do ar, diminuição da produção do ozônio, da radiação solar e de partículas poluentes. Para usufruir esses benefícios, deve-se optar por árvores com copas densas e grupos de árvores que funcionem melhor em comparação a indivíduos isolados ou plantados em linha, com atenção especial para o tipo de árvore ideal para a região a ser implementada (SPANGENBERG et al., 2008).

O direito à cidade pode ser formulado como direito à vida urbana, transformada e renovada (LEFEBVRE, 1991, p. 116). Lefebvre (1991, p. 117) aponta que o direito à cidade seria uma exigência, quase um apelo no que se refere ao direito à vida urbana em sua plenitude. $\mathrm{O}$ acesso às cidades, a partir de seu valor de uso, garantiria a virtualidade do agir aos seus habitantes. Nesta contribuição do autor, cabe refletirmos sobre a necessidade de arborização nas áreas urbanas.

Lefebvre (1991) diz que a cidade seria uma obra de agentes históricos e sociais, representando uma mediação entre a que ele chama de ordem próxima e ordem distante. O autor entende como ordem próxima as relações que se estabelecem entre os indivíduos e grupos relativamente amplos (famílias, vizinhança, corporações, entre outros), enquanto que a ordem distante é "regida por grandes e poderosas instituições", com destaque para o Estado (Lefebvre, 1991, p. 46).

A ordem próxima e a ordem distante, portanto, representam a produção do urbano a partir de diferentes grupos sociais, em nível macro e micro, definindo 
uma pluralidade de agências. Tal relação entre ambas termina por demarcar a cidade, contendo e mantendo a ordem próxima e se sustentando através de uma ordem distante, projetando-a sobre o espaço. No entanto, a ordem próxima não é pré-definida, ela também toma para si o imediato temporal e espacial por meio das ações cotidianas (Lefebvre, 1991, p. 52).

Tuan (1983, p.83) afirma que "espaços" transformam-se em "lugares" quando permitem que o indivíduo desenvolva alguma forma de afetividade com o local em que se vive ou se mantém relações, possível a partir da experiência urbana. Para Tuan (1983, p. 19), "quando o espaço nos é inteiramente familiar, torna-se lugar". Segundo o autor, espaço e lugar se relacionam em três tipos principais de espaços: o mítico, o pragmático e o abstrato. O espaço ganha status de lugar na medida em que é valorizado e experienciado, trazendo significação para as pessoas, enquanto que a definição de lugar é mais concreta do que o espaço.

A partir desta contextualização, realizou-se uma análise do Plano Diretor de Arborização Urbana (PDAU) do município de Salvador, capital do estado da Bahia. Para isso. O instrumento legal que estabelece o PDAU municipal, a partir da Lei ${ }^{\circ}$ 9.187, de 17 de janeiro de 2017, é conceituado da seguinte forma:

Instrumento permanente para definição de diretrizes e estratégias para o planejamento, implantação, reposição, expansão, manejo e manutenção da arborização e áreas verdes urbanas, prevendo-se a participação ativa da população, visando à conservação, à preservação e à ampliação da arborização (SALVADOR, 2017).

Além de promover uma sensação de bem-estar nas pessoas, as árvores promovem a qualidade de vida e ambiental, valorizam áreas abandonadas das cidades e traz benefícios para a economia. Para Wolf (2009), árvores plantadas ao longo das vias também proporcionam conforto visual e as suas sombras melhoram a performance da pavimentação das ruas, o que pode reduzir gastos públicos com a manutenção. 
Ao considerar a arborização urbana como elemento essencial para o planejamento das cidades, em que vários elementos e interesses devem ser compatibilizados, este artigo tem como objetivo analisar as perspectivas, possibilidades e desafios da arborização urbana no município de Salvador, capital da Bahia, a partir da aprovação e implantação do Plano Diretor de Arborização Urbana (PDAU). Também se buscou caracterizar os padrões estabelecidos na legislação do município.

\section{MATERIAIS E MÉTODOS}

As análises foram fundamentadas com base na interpretação da Lei 9.187/2017 (SALVADOR, 2017), com destaque para elementos quanto à sua metodologia, diagnóstico e estratégias, além do suporte da pesquisa bibliográfica. Foi realizado ainda contato com a prefeitura local, para obtenção de informações atualizadas sobre o PDAU. A discussão foi fundamentada nos princípios da legislação, considerando a importância do instrumento para o meio ambiente e para construção de uma sociedade socioambientalmente responsável e sustentável.

O município de Salvador foi escolhido para análise por adotar o PDAU, que é um instrumento legal relativamente novo, e também em decorrência da disponibilidade de acesso aos dados e informações. As etapas deste estudo consistiram em pesquisa bibliográfica e documental, com a análise do Plano Diretor de Arborização Urbana (PDAU) e levantamento de dados em fontes de pesquisa secundárias como leis, artigos, periódicos, inventários, diagnósticos e relatórios.

Capital do estado da Bahia, o município de Salvador está localizado sob o domínio do bioma Mata Atlântica. Possui uma área territorial de 693,453 km² e população estimada de 2.675 .656 habitantes (IBGE, 2020), com densidade demográfica de 3.859,44 hab/km² (IBGE, 2020). Apesar de toda a extensão 
territorial, o município ocupa a penúltima posição em arborização urbana entre as nove capitais do Nordeste (IBGE, 2017).

\section{RESULTADOS E DISCUSSÃO}

Após análise da legislação vigente, verificou-se que, antes do ano de 2017, em que foi publicada a Lei 9.187/2017 (SALVADOR, 2017), poucos instrumentos legais abordavam a prática da arborização no município de Salvador. Os principais instrumentos que buscavam cumprir este papel eram a Lei $\mathrm{n}^{\circ}$ 5.493/1999 (SALVADOR, 1999), que previa a conservação, preservação, poda, agressão, erradicação e reposição de árvores no município; e a Lei n 4.456/1991, que tratava do plantio de árvores frutíferas nas avenidas de vale ou que disponham de áreas marginais favoráveis (SALVADOR, 1991).

Sobre a arborização urbana, compreendemos que a sua dinâmica é caracterizada, entre outras coisas, pelo plantio de árvores de porte em alamedas, fundos de vale, lotes, parques, praças e vias, quer sejam de uso privado ou público. O processo de arborização, para ser bem estruturado, deve ser constituído como uma das atividades de gestão pública que ofereça atenção especial aos planos, projetos e programas urbanísticos para as cidades, e deve ser associado ao planejamento ambiental. Os benefícios incluem o bem-estar da população, valorização do turismo local, contribuições para a qualidade ambiental e benefícios para a economia, com a valorização e aproveitamento de áreas degradadas ou abandonadas das cidades.

A Constituição Federal (BRASIL, 1988), no artigo $182^{\circ}$, prevê que um Plano Diretor deve ser constituído a partir da promulgação de lei municipal, desta forma, passa-se a sua implementação para responsabilidade direta dos municípios. O instrumento deve prever e subsidiar o planejamento territorial e a sua gestão, ordenar o desenvolvimento urbano, garantir o cumprimento de funções sociais e promover o bem-estar das comunidades envolvidas. 
Sendo assim, as árvores incorporam características de uso abrangentes nas cidades, pois também servem para diminuir ruídos e oferecer melhorias no aspecto visual e paisagístico, com características e formas que podem e devem ser exploradas. Também são removedoras de gases e partículas poluentes da atmosfera, aumentam a satisfação dos cidadãos que usufruem dos espaços arborizados, seja para lazer, prática de esporte e exercícios ao ar livre, encontros e rodas de conversa, dentre outras formas de utilização, proporcionando estímulos à sensibilidade humana.

Retomando as discussões sobre os instrumentos legais, os municípios podem propor leis que abordem a política urbana desde que a sua abrangência não ultrapasse os seus limites territoriais. As diretrizes, no entanto, devem acompanhar o que dispõe o Plano Diretor em questão e a sua abrangência, seja em áreas urbanas ou rurais (GALIL, 2005). Para que um plano diretor seja completo, deve contemplar, também, a implementação de um PDAU, que servirá como instrumento de gestão e planejamento municipal das áreas verdes das cidades.

Observou-se que a Prefeitura Municipal de Salvador disponibiliza para a população o texto do PDAU na íntegra. A estrutura da Lei 9.187/2017 (SALVADOR, 2017), que institui o instrumento, está dividida em sete capítulos. Como aspectos positivos, destacamos os critérios que devem nortear a seleção e o plantio das espécies, considerando as especificidades de cada região urbana. Há ainda uma série de referências quanto a espécies arbóreas que devem ser evitadas, seja pela superficialidade ou profundidade das suas raízes, por serem espécies exóticas, pela fragilidade (ataque e/ou resistência a pragas) ou espécies com princípios tóxicos, que poderiam causar prejuízos para a comunidade.

Em seu capítulo VI, Art. 9 ${ }^{\circ}$ o PDAU condiciona e estabelece a implementação de quatro instrumentos essenciais para o seu bom funcionamento: I - Guia de Produção de Mudas; II - Manual de Arborização 
Urbana; III - Manual Técnico de Podas; e IV - Manual de Transplantio. Destes, apenas dois instrumentos estão finalizados, que correspondem aos itens II e III.

O Manual Técnico de Arborização Urbana de Salvador, instrumento que atende a uma demanda histórica na área, foi discutido e aprovado pelo Conselho Municipal do Meio Ambiente do Município de Salvador (COMAM). Além de servir para a conservação e popularizar de espécies arbóreas nativas da Mata Atlântica, o manual funciona como guia técnico e instrumento legal para orientar profissionais e cidadãos na escolha adequada de espécies. A publicação foi a primeira regulamentada pelo PDAU (SALVADOR, 2017).

Sabendo-se que a Salvador possui ruas e calçadas estreitas em alguns bairros, o manual estabelece orientações técnicas para o plantio, como largura mínima, acessibilidade e atenção a elementos urbanos como hidrantes e sinalizações de trânsito. Para harmonizar o desenvolvimento arbóreo com a circulação de pedestres, o manual orienta sobre a largura recomendada e chama a atenção para a priorização de espécies que evitem danos às calçadas e aos sistemas subterrâneos ou aéreos (telefonia, eletricidade, água e esgoto). Define ainda alguns critérios que precisam ser analisados: porte da espécie escolhida, formato da copa e adaptação da arvore ao clima da cidade.

O manual dispõe ainda de um guia de espécies da Mata Atlântica recomendadas para a arborização, um acervo de fotografias e ficha técnica com 50 espécies de árvores indicadas para o plantio nos limites do município. Outras informações técnicas indicam o porte ideal das árvores, folhagens e ambiente de origem. O último capítulo é dedicado às penalidades para quem infringir a lei, como a aplicação de multas, apreensão de materiais ou equipamentos, perda de bens, suspensão da licença ou mesmo a cassação do alvará (SALVADOR, 2017).

Conforme descrito de forma mais detalhada na Tabela 1, segundo dados do IBGE (2017), Salvador ocupa a penúltima posição, entre as nove capitais do Nordeste, quando são analisados o percentual de arborização em vias públicas. 0 município de Salvador só fica atrás de São Luís, capital do Maranhão, que ocupa a 
última posição no ranking. De acordo com os dados, João Pessoa (PB) é considerado o município mais arborizado do Nordeste, seguido por Fortaleza (CE) e Teresina $(\mathrm{PI})$, respectivamente.

Tabela 1 - Arborização nas vias públicas nas capitais do Nordeste

\begin{tabular}{lcccc}
\hline \multicolumn{1}{c}{ Município } & $\begin{array}{c}\text { Arborização de } \\
\text { vias públicas }\end{array}$ & No País & No Estado & Na microrregião \\
\hline João Pessoa (PB) & $78,4 \%$ & $2525^{\circ}$ & $180^{\circ}$ & $1^{\circ}$ \\
Fortaleza (CE) & $74,8 \%$ & $2779^{\circ}$ & $157^{\circ}$ & $2^{\circ}$ \\
Teresina (PI) & $72,3 \%$ & $2973^{\circ}$ & $119^{\circ}$ & $4^{\circ}$ \\
Recife (PE) & $60,5 \%$ & $3654^{\circ}$ & $107^{\circ}$ & $1^{\circ}$ \\
Maceió (AL) & $57,1 \%$ & $3844^{\circ}$ & $58^{\circ}$ & $6^{\circ}$ \\
Aracaju (SE) & $56,6 \%$ & $3860^{\circ}$ & $27^{\circ}$ & $1^{\circ}$ \\
Natal (RN) & $44,7 \%$ & $4331^{\circ}$ & $143^{\circ}$ & $1^{\circ}$ \\
Salvador (BA) & $39,5 \%$ & $4532^{\circ}$ & $358^{\circ}$ & $7^{\circ}$ \\
São Luís (MA) & $32,3 \%$ & $4783^{\circ}$ & $172^{\circ}$ & $1^{\circ}$ \\
\hline
\end{tabular}

Fonte: IBGE (2017)

Apesar de ser referente ao ano de lançamento do PDAU, em 2017, os dados divulgados pelo IBGE evidenciam a ineficiência da administração pública no município de Salvador quando se trata do planejamento e manutenção da arborização urbana. Esta realidade, constatada no município, a partir da análise dos indicadores do IBGE, é refletida no próprio meio ambiente e demonstrada no mapa abaixo.

Um planejamento urbano eficiente beneficia toda a população, como afirmam Spangenberg (2008) e Herrmann (2008). Constata-se, a partir dos indicadores do IBGE, que em Salvador a efetividade do PDAU ainda é negligenciada. Um planejamento público eficiente pode ser benéfico para qualquer cidade, para a biodiversidade e, consequentemente, para os seus habitantes, quando realizado de forma comprometida e participativa. Acredita-se, no entanto, que o cenário da arborização em Salvador poderá ser modificado nos 
próximos anos, sobretudo com o cumprimento da legislação e sua devida fiscalização.

Figura 1 - Mapa com percentual de arborização urbana nas capitais do Nordeste

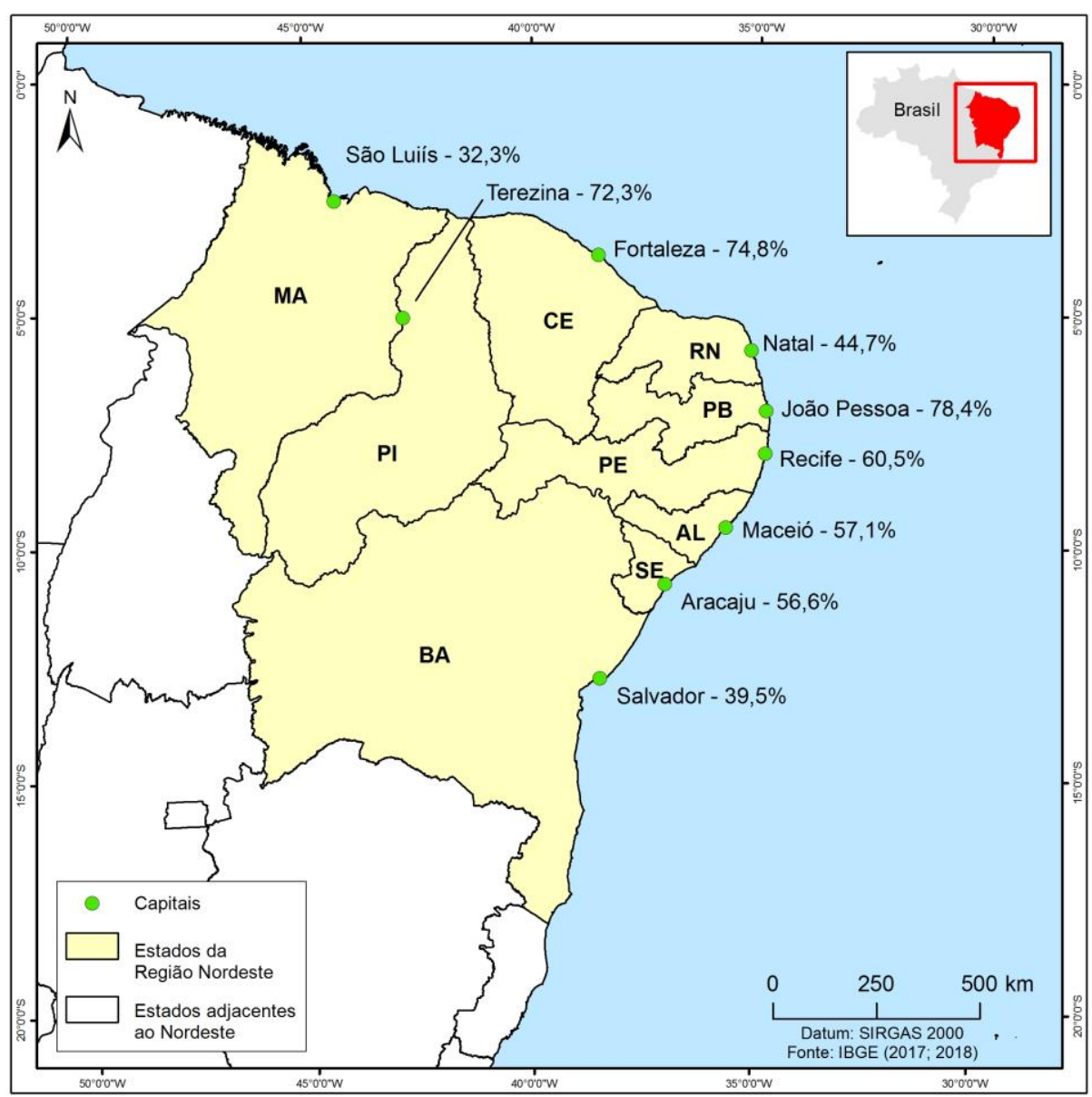

Fonte: Marcos Paulo Sales e Luís Paixão (2020)

Legenda: Mapa da região Nordeste do Brasil com os percentuais de arborização por município

\section{CONCLUSÕES}

Percebeu-se que um dos pontos importantes do PDAU é a escolha das árvores a partir de critérios técnicos. Esta decisão mostra-se benéfica para a cidade e para o meio ambiente por evitar transtornos à biodiversidade e à comunidade. Isso será importante, por exemplo, para atender às necessidades ambientais e da coletividade, e propor diretrizes que vão do planejamento até o plantio e manutenção das árvores. As características das espécies, seja para 
atender aos interesses ambientais, paisagísticos, arquitetônicos ou botânicos, deverão nortear a escolha dessas espécies.

Entre os principais conflitos observados na legislação, estão a difícil conciliação entre as diversas espécies e o local escolhido para plantio das árvores, cenário pode ser facilmente observado nas ruas de Salvador. Independente da região geográfica, as dimensões das árvores que compõem o cenário urbano geralmente são inadequadas ao local. Soma-se a isso as dimensões reduzidas de áreas urbanas disponíveis, falta de manutenção e cuidados adequados para a durabilidade das árvores.

Outro ponto observado é a utilização de algumas espécies exóticas, preteridas em relação às espécies da Mata Atlântica. As espécies nativas, quando utilizadas de forma correta e com o manejo adequado, agregam valores em todo o processo, estimulam a presença de fauna endêmica, contribuem para a conservação da biodiversidade e melhoram a paisagem urbanística local.

Os conflitos elencados poderiam ser, em boa parte, solucionados a partir do conhecimento da população sobre o PDAU, com um amplo processo de divulgação do instrumento. E isso também inclui o estímulo para sensibilizar a população sobre a importância da arborização e para a devida utilização das espécies arbóreas nativas adequadas.

A arborização é essencial para a qualidade de vida e não pode ser negligenciada. $O$ ato de arborizar as cidades, de forma planejada, atua em diversos aspectos, a exemplo da absorção de ruídos, diminuição e atenuação do calor do sol, benefícios para a biodiversidade. Em outra perspectiva, influenciam na diminuição do sentimento de opressão em relação às grandes edificações, cada vez mais comuns.

Por todas estas considerações, compreende-se a cidade como uma construção coletiva, onde se compartilham percepções, concepções e experiências de mundo, resultado de vínculos das relações sociais com a 
natureza, formando um espaço de encontros e constituição das diferenças. Neste aspecto, a participação da população nesta construção é fundamental.

\section{CONSIDERAÇÕES FINAIS}

Pode-se concluir que os indicadores da arborização nas cidades, abordados neste estudo, poderiam ser utilizados para diversas ações, como para efetuar a divisão geográfica nas áreas urbanas, por exemplo. O ambiente físico das cidades influencia as pessoas e os efeitos positivos da implantação do PDAU poderiam sugerir direções a projetos mais humanos, sustentáveis e ambientalmente adequados.

Nesse contexto, ações de educação ambiental não formal, se implementadas, serviriam para sensibilização e percepção da sociedade sobre a importância do tema da arborização urbana, considerada elemento indispensável para a melhoria da qualidade de vida da população, valorização de áreas urbanas e manutenção da fauna e flora locais. Ressaltamos, no entanto, que outras pesquisas devem ser realizadas para comprovação ou não dessas hipóteses.

\section{REFERÊNCIAS}

ARAÚJO, Sucfy Mara Váz Guimarães de. O Estatuto da Cidade e a questão ambiental. Brasília: Câmara dos Deputados, 2003. Disponível em: http://www2.camara.gov.br/pubhcacoes/estnoiiec/tema 14/pdí73043íi6.pdf. Acesso em: 22 fev. 2021.

BERNATZKY, A. Tree ecology and preservation. 2 ed. Amsterdam: Elsevier, 1980. 357p. BRASIL. Constituição da República Federativa do Brasil, 1988. São Paulo. BONAMETTI, João Henrique. Arborização Urbana. Terra e Cultura, Ano XIX, n 36, p. 51- 54, 2003.

BRAGA, R. Política urbana e gestão ambiental: considerações sobre o plano diretor e zoneamento urbano. In: CARVALHO, P.F.; BRAGA, R. Perspectiva de gestão ambiental em cidades médias. Rio Claro: LPM-UNESP, 2001. p. 95-109. 
CARVALHO, Pompeu Figueiredo. Repensando as áreas verdes urbanas. Rio Claro: Unesp, Território e Cidadania, 2003.

DE ARAÚJO JUNIOR, Miguel Etinger. Algumas considerações sobre o Plano Diretor dos municípios e sua importância no processo de construção da cidadania e da democracia. Revista do Direito Público, v. 1, n. 1, p. 45-62, 2005.

EMBRAPA. Boletim, 2000. Disponível em: http://www.cnpf.embrapa.br/publica/boletim/boletarqv/boletim18_19/baggio.pdf. Acesso em: 10 jan. 2021.

GALIL, A. M. G. O direito urbanístico no Brasil: aspectos estratégicos para a elaboração do plano diretor. Centro de Pesquisas Estratégicas "Paulino Soares", Juiz de Fora: UFJF, nov 2005, 20 p.

HERRMANN, C. R. A. A qualidade do sombreamento de espécies arbóreas e sua influência no microclima do entorno imediato em ambientes urbanos. 2008. $160 \mathrm{f}$. Dissertação (Mestrado em Engenharia do Meio Ambiente) - Escola de Engenharia Civil, Universidade Federal de Goiás, Goiânia. 2008.

IBGE - Instituto Brasileiro de Geografia e Estatística. Atlas do censo demográfico. Disponível em: http://censo2010.ibge.gov.br/apps/atlas/. Acesso em: 8 mar. 2021.

LEFEBVRE, Henri. O direito à cidade. São Paulo: Moraes, 1991.

MMA - MINISTÉRIO DO MEIO AMBIENTE. Biodiversidade brasileira: avaliação e identificação de áreas e ações prioritárias para a conservação, utilização sustentável e repartição dos benefícios da biodiversidade nos biomas brasileiros. Secretaria de Biodiversidade e Florestas, MMA, Brasília, 2002.

NASCIMENTO, D. T. N. \& CAMPOS, E. T. Instrumentos de planejamento territorial urbano: plano diretor, estatuto da cidade e a agenda 21. In: CONGRESSO BRASILEIRO DE CADASTRO TÉCNICO MULTIFINALITÁRIO, 2006, Florianópolis, 10 p.

PINHEIRO, C. B.; SOUZA, D. D. A importância da arborização nas cidades e sua influência no microclima. Revista Gestão \& Sustentabilidade Ambiental, Florianópolis, v. 6, n. 1, p. 67-82, 2017.

SALVADOR. Lei $\mathrm{n}^{\circ}$ 9.187, de 17 de janeiro de 2017. Dispõe sobre o Plano Diretor de Arborização Urbana do Município de Salvador. Salvador: Câmara Municipal, [2017]. Disponível em: http://www.sucom.ba.gov.br/wp-content/uploads/2017/01/Lei_9187_2017.pdf. Acesso em: 22 fev. 2021.

SPANGENBERG, J. et al. Simulation of the Influence of Vegetation on Microclimate and Thermal Comfort in the City of São Paulo. Revista da Sociedade Brasileira de Arborização Urbana, Piracicaba - SP, v. 3, n. 2, p. 1-19, 2008.

SANTOS, Milton. Metamorfoses do Espaço Habitado. São Paulo: EDUSP, 2008. SANTOS, M. (2002). $O$ espaço do cidadão. São Paulo, Edusp. 
TAHA, H.; DOUGLAS S.; HANEY, J. Mesoscale meteorological and air quality impacts of increased urban albedo and vegetation. Energy and Buildings, USA, v. 25, 1997.

TOZZI, Rodrigo Henrique Branquinho Barboza. A tutela jurídica da arborização urbana. In: Âmbito Jurídico, Rio Grande, XX, n. 159, abr 2017. Disponível em: http://ambitojuridico.com.br/site/?n_link=revista_artigos_leitura\&artigo_id=18708\&revista_cad erno=5. Acesso em: 10 fev. 2021.

TUAN, Y. -F. Espaço e Lugar: a perspectiva da experiência. São Paulo: DIFEL, 1983.

WOLF, K. L. A economia e o valor público das florestas urbanas. Revista de Agricultura Urbana, Havana, n. $13 . \quad$ Disponível em: http://www.ipes.org/index.php?option=com_content\&view=article\&id=111\&ltemid=135. Acesso em: 21 jan. 2021.

\section{Contribuição de autoria}

\section{1 - Marcos Paulo Sales}

Doutorando em Mudança Social e Participação Política https://orcid.org/0000-0002-0853-6358•mp.sales@gmail.com Contribuição: Conceituação, Metodologia, Análise Formal, Investigação, Curadoria de dados, Escrita - Primeira Redação, Escrita - Revisão e Edição, Administração do Projeto

\section{2 - Geraldo Jorge Barbosa de Moura}

Programa de Pós-graduação em Planejamento Ambiental https://orcid.org/0000-0001-6035-516X・geraldojbn@gmail.com

Contribuição: Conceituação, Metodologia, Validação, Análise Formal, Investigação, Escrita Revisão e Edição, Administração do Projeto

\section{3 - André Augusto Araújo Oliveira}

Mestrando do Programa de Pós-graduação em Território, Ambiente e Sociedade https://orcid.org/0000-0001-9028-3400•andreaa.oliveira@ucsal.edu.br Contribuição: Conceituação, Investigação, Curadoria, Escrita - Primeira Redação

\section{4 - Ronaldo Souza Piber}

Advogado, graduando em Ciências Biológicas

https://orcid.org/0000-0002-1020-2189•rspiber@gmail.com

Contribuição: Conceituação, Investigação, Curadoria de dados, Escrita - Primeira Redação

\section{Como citar este artigo}

SALES; et al. Cidades verdes: uma análise do Plano Diretor de Arborização Urbana do município de Salvador (BA). Revista Monografias Ambientais, Santa Maria, v. 20, e1, 2021. DOI 10.5902/2236130862962. Disponível em: https://doi.org/10.5902/2236130862962. Acesso em: dia mês abreviado. ano. 